\title{
Eficiência de Metarhizium anisopliae no controle do Percevejo-do-Colmo Tibraca limbativentris (Heteroptera: Pentatomidae) em lavoura de arroz irrigado
}

\author{
Efficiency of Metarhizium anisopliae on rice stem bug Tibraca limbativentris \\ (Heteroptera: Pentatomidae) control in flooded rice field
}

\author{
José Francisco da Silva Martinss ${ }^{1}$ Marcos Botton $^{2}$ Jairo João Carbonari ${ }^{3}$ \\ Eliane Dias Quintela ${ }^{4}$
}

\section{RESUMO}

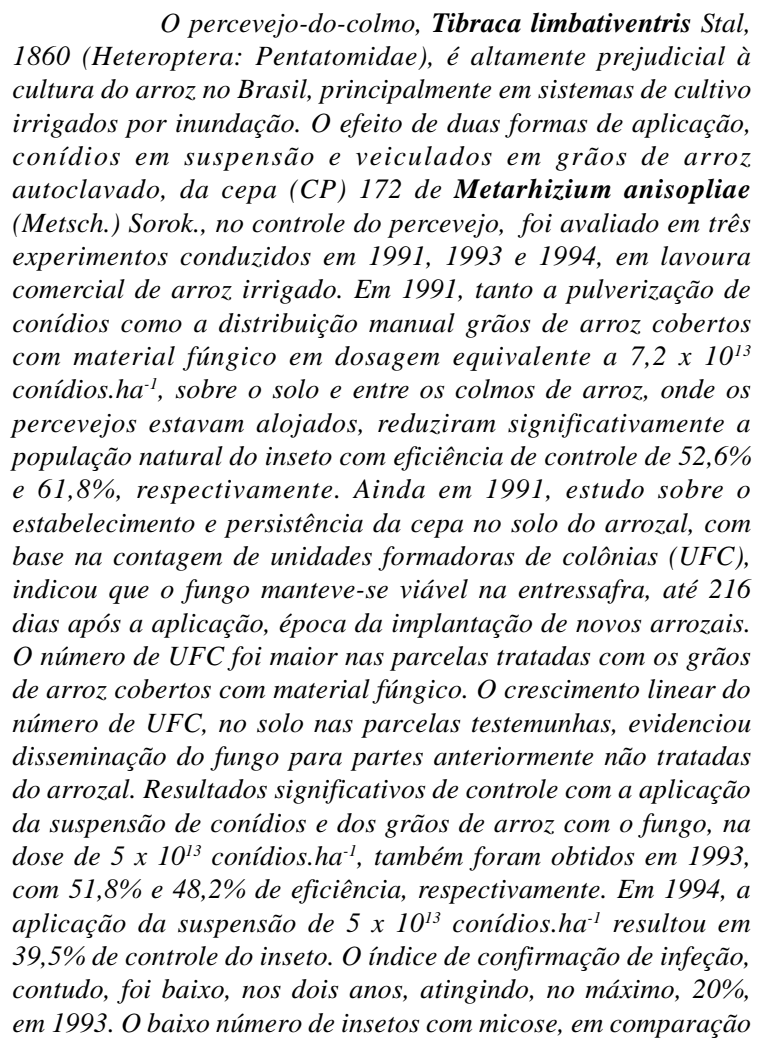

ao índice de mortalidade, pode provavelmente reduzir a taxa de disseminação do fungo nos arrozais e, por conseqüência, ser desfavorável à ocorrência de epizootias.

Palavras-chave: insecta, Oryza sativa, controle microbiológico, persistência no solo.

\section{ABSTRACT}

The rice stem bug, Tibraca limbativentris Stal, 1860 (Heteroptera: Pentatomidae), is an important pest of rice (Oryza sativa L.) in Brazil, mainly in flooded system of cultivation. The effect of two ways of application (conidia in aqueous suspension and on rice grain) of Metarhizium anisopliae strain 172 for the control of the rice stem bug, was evaluated in three experiments conducted in 1991, 1992 and 1994 in commercial irrigated rice. In 1991, the spraying of conidia suspension and manual distribution of rice grain covered with fungal material at dose of $7.2 \times 10^{13}$ conidia.ha ${ }^{-1}$, on soil and among rice stems, where the bugs were located, reduced significantly the insect natural population with control efficiencies of 52.6 and $61.8 \%$, respectively. Studies about establishment and persistence of fungal conidia in soil, using the colony forming unity (CFU) counts, indicated that the fungus persisted in the soil between two rice crop seasons, up to 216 days after application, when new rice crops were established. The number of $C F U$ was greater in the plots treated with rice grain covered with fungal material. The linear growth of $\mathrm{CFU}$ in the control plots showed that the fungus spread to the untreated areas of the rice field. Significant control efficiency was obtained in 1993 for grain and aqueous fungus treatment with $48.2 \%$ and $51.8 \%$, respectively. In 1994, the conidial suspension at dose of $5 \times 10^{13}$ conidia.ha ${ }^{-1}$ resulted in control efficiency of $39.5 \%$. The level of insect mycosis, however,

\footnotetext{
${ }^{1}$ Engenheiro Agrônomo, Doutor, Embrapa Clima Temperado, CP 403, 96001-970, Pelotas, RS. E-mail: martins@cpact.embrapa.br ${ }^{2}$ Engenheiro Agrônomo, Doutor, Embrapa Uva e Vinho, CP 130, 95700-000, Bento Gonçalves, RS. E-mail: marcos@cnpuv.embrapa.br ${ }^{3}$ Engenheiro Agrônomo, Doutor, Mistério da Agricultura, Pecuária e Abastecimento, Divisão de Defesa Vegetal, Av. Loureiro da Silva, 515 , Sala 509, 90010-420, Porto Alegre, RS. E-mail: carbonari@agricultura.gov.br

${ }^{4}$ Engenheiro Agrônomo, PhD, Embrapa Arroz e Feijão, CP 179, 75375-000, Santo Antônio de Goiás, GO. E-mail: quintela@cnpaf.embrapa.br
} 
was low in both 1993 and 1994, reaching a maximum of 20\% mycosis in 1993. The low numbers of insect with mycosis compared with the level of mortality, may probably reduce the rate of fungal dissemination in rice fields and, consequently, be detrimental to the occurrence of epizootics.

Key words: Insecta, Oryza sativa, microbial control, entomopathogenic fungus, soil persistence.

\section{INTRODUÇÃO}

O percevejo-do-colmo Tibraca limbativentris (Heteroptera: Pentatomidae) é altamente prejudicial à cultura do arroz no Brasil (FERREIRA et al., 1986), principalmente em cultivos irrigados por inundação. Esse inseto danifica as plantas de arroz desde o início da fase de perfilhamento, porém, danos econômicos à cultura ocorrem quando perfura os colmos entre a fase de pré-floração e a de formação de panículas (COSTA \& LINK, 1992a).

$\mathrm{Na}$ entressafra, o percevejo-do-colmo hiberna na base de plantas, de diversas espécies, junto à superfície do solo, onde há maior umidade (LINK et al., 1997). Migrando aos novos arrozais, localizase também na base das plantas de arroz, entre os colmos, preferencialmente onde não há formação de lâmina d'água de irrigação, estando o solo apenas saturado (BOTTON et al., 1996). Nesses locais, ocorrem condições de umidade e temperaturas propícias ao desenvolvimento do inseto (MARTINS \& LIMA, 1994) e de fungos entomopatogênicos (CARBONELL et al., 1980).

Pesquisas pioneiras sobre o efeito de fungos entomopatogênicos em percevejos que atacam o colmo do arroz, foram realizadas na Ásia, envolvendo, principalmente, o pentatomídeo Scotinophara coarctata (F.) e os fungos Metarhizium anisopliae (Metsch.) Sorok. e Beauveria bassiana (Bals.) Vuill. (ROMBACH et al., 1986). No Brasil, pesquisas similares com T. limbativentris foram iniciadas com base na premissa de que o hábito de localização do inseto e as condições micro-meteorológicas entre os colmos de arroz seriam adequadas ao estabelecimento e disseminação de fungos entomopatogênicos em arrozais (MARTINS \& LIMA, 1994). Avaliações iniciais em laboratório, simulando condições de campo favoráveis ao crescimento da população de $\boldsymbol{T}$. limbativentris, permitiram identificar isolados de $\boldsymbol{B}$. bassiana e $M$. anisopliae virulentos aos insetos conforme resultados apresentados por MARTINS \& LIMA, 1994. Uma segunda etapa de avaliação envolveu três experimentos, realizados no campo, incluindo infestação artificial de plantas de arroz, em gaiolas, com adultos de T. limbativentris e aplicação de isolados de M. anisopliae e B. bassiana, na forma de suspensão de conídios ou por meio de grãos de arroz cobertos com material fúngico (MARTINS et al., 1997). A suspensão de conídios tendeu a ser mais eficiente e a CP 164 de Beauveria e as CPs 171 e 172 de Metarhizium proporcionaram maiores índices de mortalidade, confirmando a condição de promissoras para controle biológico do inseto. Porém, o índice de insetos mortos com infeção fúngica confirmada foi baixo, em relação a todos os isolados testados, nos três experimentos, aspecto contrário a uma maior taxa de disseminação dos fungos nos arrozais, o que pode dificultar o estabelecimento de epizootias.

A implantação do controle de $\boldsymbol{T}$. limbativentris por meio de fungos entomopatogênicos pode ser facilitada se o manejo do material fúngico for realizado de acordo com a dinâmica populacional do inseto nos arrozais. Os adultos pós-hibernantes acasalam, predominantemente em focos, às margens dos arrozais, na fase vegetativa das plantas (COSTA \& LINK, 1992b). Nestes locais, a progênie (ninfal) permanece concentrada até a distribuição, ao acaso, dos adultos da primeira geração anual, retornando o inseto à distribuição agregada, na fase reprodutiva das plantas, sempre havendo maior acúmulo populacional em locais não atingidos pela lâmina da água de irrigação. Portanto, a aplicação de entomopatógenos ao final da fase ninfal da primeira geração anual, atingindo simultaneamente ninfas e adultos, seria a melhor estratégia para reduzir a população do inseto, ainda nos focos iniciais de infestação. Adultos remanescentes, contaminados, ao distribuírem-se ao acaso, disseminariam os entomopatógenos nos arrozais.

Este trabalho objetivou continuar a avaliação do efeito de fungos entomopatogênicos sobre T. limbativentris, envolvendo formas de aplicação da CP 172 de M. anisopliae, reconhecida como promissora para o controle do inseto, em condições de lavoura comercial de arroz irrigado.

\section{MATERIAL E MÉTODOS}

A cepa de M. anisopliae (CP 172) foi originalmente isolada de adultos de T. limbativentris, em casa de vegetação, da Embrapa Arroz e Feijão, em Santo Antônio de Goiás, GO. Esta cepa está armazenado na Embrapa Recursos Genéticos e Biotecnologia, em Brasília, DF sob número CG 168. Para o estudo, o material fúngico foi produzido em sacos de polipropileno, contendo grãos de arroz descascados, autoclavados e mantidos à temperatura de $27 \pm 1^{\circ} \mathrm{C}$, por 15 dias (MARQUES et al., 1981; 
QUINTELA, 1994). A viabilidade dos conídios, superior a $90 \%$, foi aferida pelo método de germinação, via espalhamento uniforme de 100 microlitros da suspensão dos conídios em meio de cultura BDA + estreptomicina em placas de Petri (90 $\mathrm{mm}$ ), em três repetições. As placas foram mantidas em estufa incubadora, à $26 \pm 1^{\circ} \mathrm{C}$, por 18 horas, quando foi efetuada a avaliação da germinação.

Três experimentos foram implantados em lavoura comercial de arroz, irrigado com a cultivar BR IRGA 410, no Município de Rosário do Sul, RS, em 1991, 1993 e 1994. No primeiro experimento, foram avaliados quatro tratamentos, $M$. anisopliae aplicado (1) na forma de conídios e micélios veiculados em grãos de arroz, (2) em suspensão de conídios, (3) inseticida químico monocrotofós (incluído como padrão) e (4) testemunha sem aplicação, em blocos casualizados, com oito repetições. A suspensão de conídios, na dose de 7,2 x $10^{13}$ conídios.ha ${ }^{-1}$, foi preparada com água destilada + $0,5 \%$ de Tween 80 e os conídios veiculados em grãos de arroz consistiram dos próprios grãos de arroz usados para produção do material fúngico. Os blocos consistiram de seções de taipas (camalhões de terra que represam a água de irrigação sobre os quais o arroz também foi cultivado) com 50m de comprimento e as parcelas experimentais de subseções com $5 \mathrm{~m}$, eqüidistantes $10 \mathrm{~m}$. Na data da aplicação da CP 172 (ao final da fase de perfilhamento das plantas), foi realizada a aferição (pré-contagem) da população de percevejos, em espaço de $1 \mathrm{~m}^{2}(0,5 \mathrm{~m}$ de largura e $2 \mathrm{~m}$ de comprimento), no topo das taipas.

A suspensão de conídios foi aplicada com pulverizador propelido a $\mathrm{CO}_{2}$, equipado com bico leque, gastando 360L.ha-1. A aplicação foi realizada entre as plantas de arroz, no sentido do comprimento da taipa, de modo que o jato atingisse simultaneamente a superfície do solo e a base dos colmos, até cerca de $20 \mathrm{~cm}$ de altura. Duzentos gramas de grãos cobertos com micélios e conídios foram distribuídos, manualmente, na área da parcela (equivalente a 7,2 x $10^{13}$ conídios.ha-1), também no sentido do comprimento da taipa, atingindo a superfície do solo ou alojando-se na base das plantas de arroz, entre os colmos. O inseticida monocrotofós [200ml (i.a.)ha ${ }^{-1}$ ] foi aplicado 16 dias após, do mesmo modo que a suspensão de conídios.

Trinta dias após a aplicação do inseticida, na época da colheita dos grãos, foi aferida a população final de percevejos também em $1 \mathrm{~m}^{2}$, no topo das taipas. As plantas de arroz foram cortadas, com foice, no nível do solo e sacudidas sobre um lenço plástico, para liberação dos insetos (ninfas e adultos), sendo o material vegetal remanescente no topo das taipas minuciosamente vasculhado, na procura de insetos.

Para avaliação da possibilidade de estabelecimento e persistência da CP 172 no solo do arrozal, na data da aplicação das duas formas do fungo (26.02.1991) e 25, 49, 91, 118, 170 e 216 (02.10.1991), dias após, foram coletadas duas amostras de solo em cada parcela experimental (na profundidade máxima de $1 \mathrm{~cm}$ ), menos naquelas inerentes ao tratamento com monocrotofós. O material coletado foi remetido ao Laboratório de Patologia de Insetos da Embrapa Arroz e Feijão. Pesaram-se 50g do solo e procederam-se diluições decimais em 450ml de água destilada e a suspensão resultante foi agitada manualmente e $0,1 \mathrm{ml}$ das diluiçõoes de $10^{-1}$ e $10^{-2}$ foram colocados em placas de Petri com meio seletivo, em três repetições por diluição. As placas foram mantidas em incubadora durante sete a dez dias, à temperatura de $26 \pm 1^{\circ} \mathrm{C}$, para contagem das unidades formadoras de colônias (UFC). O material da primeira e segunda coleta de solo foi colocado, em meio seletivo, à base de batata, dextrose 4\%, ágar e dodine 650ppm do produto comercial (Cyprex PM, Rhone-Poulenc Ag. Co., NC, EUA) (LINGG \& DONALDSON, 1981). Devido à presença de contaminantes nesse meio de cultura, a partir da terceira coleta de solo, foi utilizado o meio com aveia, ágar, dodine 450 ppm p.c. e cristal violeta (BEILHARZ et al., 1982).

No segundo experimento, em 1993, foi reavaliado o efeito dos conídios em suspensão em grãos de arroz, usando metodologia similar à adotada em 1991, caracterizada pelas seguintes alterações: (a) adoção de procedimento para confirmação de infeção de insetos, através da coleta de dez indivíduos, por parcela experimental, imediatamente após a aplicação do fungo, colocando-os em copos plásticos (com capacidade de $300 \mathrm{ml}$ ), contendo alimento renovável (pedaços de colmo de arroz), mantidos à temperatura de $25 \pm 2^{\circ} \mathrm{C}$, para observação diária. Os insetos mortos foram transferidos para placas de Petri $(90 \mathrm{~mm})$ que continnham papel filtro umedecido; (b) interrupção da coleta de amostras de solo para estudo sobre estabelecimento e persistência do fungo no solo do arrozal. No terceiro experimento, em 1994, foi usada metodologia similar à do ano anterior, porém, sem incluir a os conídios veiculados em grãos de arroz.

Para a análise de variância (SAS INSTITUTE, 1985), o número $(\mathrm{N})$ de insetos vivos e mortos infectados foi transformado em $\sqrt{ } \mathrm{N}+0,5$, sendo as médias comparadas pelo teste de Tukey (nível de 5\% de probalidade de erro). A eficiência de controle da CP 172 foi calculada pela fórmula de ABBOTT (1925). Estabeleceu-se análise de regressão 
linear entre o número de UFC/100 gramas de solo da parcela testemunha e as datas de coletas das amostras de solo.

\section{RESULTADOS E DISCUSSÃO}

Nos três experimentos, a infestação de $\boldsymbol{T}$. limbativentris foi uniforme nas parcelas destinadas aos diferentes tratamentos visto não ter sido constatada diferença significativa entre o número de insetos registrado, na pré-contagem, nas referidas parcelas (Tabelas 1e 2).

No primeiro experimento, pós-tratamentos, não ocorreu diferença significativa entre as formas de aplicação da CP 172 (suspensão de conídios e grãos cobertos com fungo) quanto ao número de percevejosdo-colmo nas parcelas (Tabela 1). Como ambas formulações reduziram significativamente a população natural do inseto, em condições de lavoura comercial, confirmam-se, portanto, os resultados obtidos em laboratório (MARTINS \& LIMA, 1994) e no campo, com infestação artificial (MARTINS et al., 1997). A aplicação do esporo do fungo em suspensão, porém, ao resultar em menor número de insetos nas parcelas, não diferiu significativamente do tratamento com o inseticida monocrotofós, o qual apresentou a maior eficiência de controle (Tabela 1).

Ocorreu formação de colônias do fungo, nas parcelas tratadas, em todas as preparações de solo (Figura 1), indicando que o fungo manteve-se viável durante a entressafra, até 216 dias pós-aplicação (DAT). Após este período, a cultura do arroz poderá ser novamente implantada e ser infestada por indivíduos pós-hibernantes de T. limbativentris, que provavelmente poderiam ser infectados com o fungo. Nas parcelas tratadas com grãos de arroz, número de unidades formadoras de colônias (UFC) foi maior que a suspensão de conídios, porque os conídios provavelmente continuaram o crescimento nos grãos (Figura 1A, B). Após 216 DAT, 70\% e 27\% do inoculo inicial do fungo das formulações granulada e líquida, respectivamente, estavam presentes nas áreas tratadas (Figura 1B). As variações, caracterizadas por aumentos e reduções, no número de UFC, no transcorrer das sete avaliações, são provavelmente, consequiência da coleta de amostras de solo ao acaso, em determinados pontos, na área das parcelas experimentais, onde havia concentrações diferentes do fungo.

Na parcela testemunha (sem aplicação do fungo) não foram isoladas colônias de $\boldsymbol{M}$. anisopliae do solo, na primeira avaliação, indicando provavelmente que o fungo não estava presente na área experimental. Normalmente, a ocorrência de $\boldsymbol{M}$. anisopliae no solo é baixa. Segundo TIGANOMILANI et al. (1993), o fungo foi detectado apenas em 6\% de 81 amostras de solo oriundas de diferentes municípios Brasileiros. QUINTELA et al. (1992) também não constataram UFC de $\boldsymbol{M}$. anisopliae em parcelas não tratadas, em experimentos sobre persistência, no Ceará. Neste trabalho, a presença de UFC no solo de parcelas testemunhas (Figura 1C), com aumento progressivo a partir da segunda avaliação, pode ter decorrido do transporte de conídios pela água de irrigação (durante o cultivo de arroz) ou das chuvas (na entressafra), em situações de acúmulo e movimentação excessiva, ou por insetos infectados pelo fungo. Independentemente da causa, a presença de UFC no solo das parcelas testemunhas constituiuse em fato positivo, indicando que houve disseminação do fungo no arrozal, principalmente, se for considerada a tendência de aumento do número de UFC, da data de aplicação do fungo até 216 DAT (Figura 1C). No segundo experimento, a suspensão de conídios e os grãos de arroz com fungo apresentaram eficiência de controle similar, significativamente inferior a do inseticida monocrotofós (Tabela 2). No terceiro experimento, foi obtido resultado semelhante com a suspensão de conídios (Tabela 2).

O menor número de percevejos nas parcelas experimentais tratadas com monocrotofós, comparativamente às parcelas testemunhas, tanto em

Tabela 1- Variação populacional de Tibraca limbativentris em locais do arrozal irrigado tratados com conídios em suspensão e em grãos de arroz da CP 172 de Metarhizium anisopliae e com o inseticida monocrotofós. Rosário do Sul, RS. $1^{\underline{9}}$ experimento. 1991 .

\begin{tabular}{|c|c|c|c|}
\hline \multirow{2}{*}{ Tratamentos } & \multicolumn{2}{|c|}{$\begin{array}{l}\text { Número médio de } \\
\text { insetos }\end{array}$} & \multirow{2}{*}{$\begin{array}{l}\text { Eficiência de } \\
\text { controle }^{2}(\%)\end{array}$} \\
\hline & $\begin{array}{c}\text { Pré- } \\
\text { aplicação }\end{array}$ & $\begin{array}{c}\text { Pós- } \\
\text { aplicação }\end{array}$ & \\
\hline Testemunha & $5,0 \mathrm{a}$ & $7,6 \mathrm{a}$ & - \\
\hline Conídios em arroz ${ }^{3}$ & $3,8 \mathrm{a}$ & $3,6 \mathrm{~b}$ & 52,6 \\
\hline Suspensão de conídios ${ }^{4}$ & $5,5 \mathrm{a}$ & $2,9 \mathrm{bc}$ & 61,8 \\
\hline Monocrotofós $^{5}$ & $4,6 \mathrm{a}$ & $1,5 \mathrm{c}$ & 80,3 \\
\hline
\end{tabular}

${ }^{1}$ Número de ninfas de $3^{\circ}, 4^{\circ}$ e $5^{\circ}$ instar e de adultos, coletados em 1 $\mathrm{m}^{2}$, no topo das taipas, antes e após a aplicação dos tratamentos. Médias não seguidas pela mesma letra diferem significativamente pelo teste de Tukey, em nível de 5\% de probabilidade de erro.

${ }^{2}$ Eficiência de controle, 16 e 45 dias após a aplicação do inseticida e do fungo, respectivamente (ABBOTT, 1925).

${ }^{3}$ Distribuição manual de 200 gramas de grãos de arroz descascados, cobertos com conídios e micélios.

${ }^{4}$ Pulverização com suspensão de conídios $\left(7,2 \times 10^{13}\right.$ conídios ha $\left.{ }^{-1}\right)$.

${ }^{5}$ Dosagem de $200 \mathrm{ml}$ (ia) ha ${ }^{-1}$. 
Tabela 2 - Variação populacional de Tibraca limbativentris em locais do arrozal irrigado tratados com conídios em suspensão e em grãos de arroz da CP 172 de Metarhizium anisopliae e com o inseticida monocrotofós, mortalidade e infeção de insetos em laboratório. Rosário do Sul, RS. $2^{\circ}$ experimento (1993) e $3^{\circ}$ experimento (1994).

\begin{tabular}{|c|c|c|c|c|c|}
\hline \multirow{3}{*}{ Tratamentos } & \multicolumn{3}{|c|}{ Arrozal irrigado } & \multicolumn{2}{|c|}{ Laboratório $^{3}$} \\
\hline & \multicolumn{2}{|c|}{ Número médio de insetos ${ }^{1,4}$} & \multirow{2}{*}{ Efic. Controle $^{2}(\%)$} & \multirow{2}{*}{ Mortalidade $^{4}(\%)$} & \multirow{2}{*}{ Micose (\%) } \\
\hline & Pré-aplicação & Pós-aplicação & & & \\
\hline \multicolumn{6}{|c|}{$2^{\underline{0}}$ experimento } \\
\hline Testemunha & $17,8 \mathrm{a}$ & $24,9 \mathrm{a}$ & - & $37,5 \mathrm{a}$ & - \\
\hline Conídios em arroz ${ }^{5}$ & $18,5 \mathrm{a}$ & $12,0 \mathrm{~b}$ & 51,8 & $32,5 \mathrm{a}$ & 15,0 \\
\hline Suspensão de conídios ${ }^{6}$ & $16,0 \mathrm{a}$ & $12,9 \mathrm{~b}$ & 48,2 & $45,0 \mathrm{a}$ & 20,0 \\
\hline Monocrotofós $^{7}$ & $20,1 \mathrm{a}$ & $3,9 \mathrm{c}$ & 84,3 & - & - \\
\hline \multicolumn{6}{|c|}{$3^{\circ}$ experimento } \\
\hline Testemunha & $13,2 \mathrm{a}$ & $43,6 \mathrm{a}$ & - & $20,0 \mathrm{a}$ & - \\
\hline Suspensão de conídios ${ }^{6}$ & $12,6 \mathrm{a}$ & $26,4 \mathrm{~b}$ & 39,5 & $80,0 \mathrm{~b}$ & 9,8 \\
\hline Monocrotofós $^{7}$ & $11,1 \mathrm{a}$ & $10,0 \mathrm{c}$ & 77,1 & - & - \\
\hline
\end{tabular}

${ }^{1}$ Número de ninfas de $3^{\mathrm{o}}, 4^{\mathrm{o}}$ e $5^{\mathrm{o}}$ instar e de insetos adultos coletados em $1 \mathrm{~m}^{2}$, no topo das taipas, antes e após a aplicação dos tratamentos.

${ }^{2}$ Eficiência de controle, 15 dias após a aplicação (ABBOT, 1925).

${ }^{3}$ Mortalidade e infeção confirmada, com base no total de 80 insetos coletados por tratamento.

${ }^{4}$ Médias não seguidas pela mesma letra diferem significativamente pelo teste de Tukey, em nível de 5\% de probabilidade de erro.

${ }^{5}$ Distribuição manual de 200 gramas de grãos de arroz descascados, cobertos com conídios e micélios.

${ }^{6}$ Pulverização com suspensão de conídios $\left(7,2 \times 10^{13}\right.$ conídios ha $\left.{ }^{-1}\right)$.

${ }^{7}$ Dosagem de $200 \mathrm{ml}$ (ia) ha ${ }^{-1}$.

1991, 1993 e 1994, indica que a aplicação em lavoura comercial de medidas de controle, mesmo em locais propensos à reinfestação, no caso parcelas abertas a campo, mantém a população do inseto reduzida. Portanto, a diferença significativa entre o menor número de percevejos nas parcelas tratadas com a $\mathrm{CP}$ 172 e o maior número nas parcelas testemunhas deve ser considerada decorrente do efeito do patógeno sobre o inseto.

A mortalidade dos percevejos coletados na lavoura imediatamente após o tratamento com a CP 172 e mantidos em laboratório, em copos plásticos, para confirmação da infeção, não foi significativa em 1993 (Tabela 2). Em 1994, porém, o resultado sobre mortalidade foi satisfatório (Tabela 2), indicando que tal metodologia deve ser melhor estudada quanto à possibilidade de avaliar, em laboratório, o efeito de fungos entomopatogênicos aplicados a campo, assim procurando evitar os problemas ocasionados pelo desaparecimento de insetos mortos (cadáveres) nas parcelas experimentais. $\mathrm{O}$ índice de confirmação de infeção, contudo, foi baixo, nos dois anos, atingindo, no máximo, 20\% em 1993. O baixo índice de crescimento da CP 172, constatado em cadáveres de T. limbativentris, pode constituir-se em fator redutor da taxa de disseminação do fungo nos arrozais e, por conseqüência, dificultar a ocorrência de epizootias. Essa constatação coincide com resultado relacionado à mesma espécie de fungo, a qual não desenvolvia epizootia em populações naturais de $S$. coarctata ou mesmo em populações confinadas em gaiolas, sendo a escassez de umidade apontada como a causa principal dos baixos índices de infeção do inseto (ROMBACH et al., 1986). Condições favoráveis de temperatura também são apontadas como essenciais para que os fungos entomopatogênicos esporulem nos cadáveres de insetos infectados (HALL \& PAPIEROK, 1982). A umidade, pelo menos, não deve ter sido um dos fatores determinantes dos baixos índices de infeção de T. limbativentris, visto a superfície do solo, entre as plantas de arroz, onde a CP 172 foi aplicada, ter sempre se mantido saturada, provavelmente atingindo os limites adequados ao desenvolvimento de fungos entomopatogênicos, sugeridos por ALVES (1986).

Várias hipóteses podem ser formuladas para explicar a baixa infeção de T. limbativentris pelo fungo: a) aplicação ao final da fase ninfal da primeira geração anual, quando os insetos estão fisiologicamente pré-dispostos à hibernação e, provavelmente, mais resistentes à ação de entomopatógenos. Estudos preliminares, em laboratório, evidenciaram que adultos de Tibraca, em hibernação, tendem a ser mais resistentes a fungos (MARTINS, dados não publicados); b) tratamento do inseto com uma concentração de 7,2 x $10^{13}$ conídios.ha ${ }^{-1}$, provavelmente muito alta, 


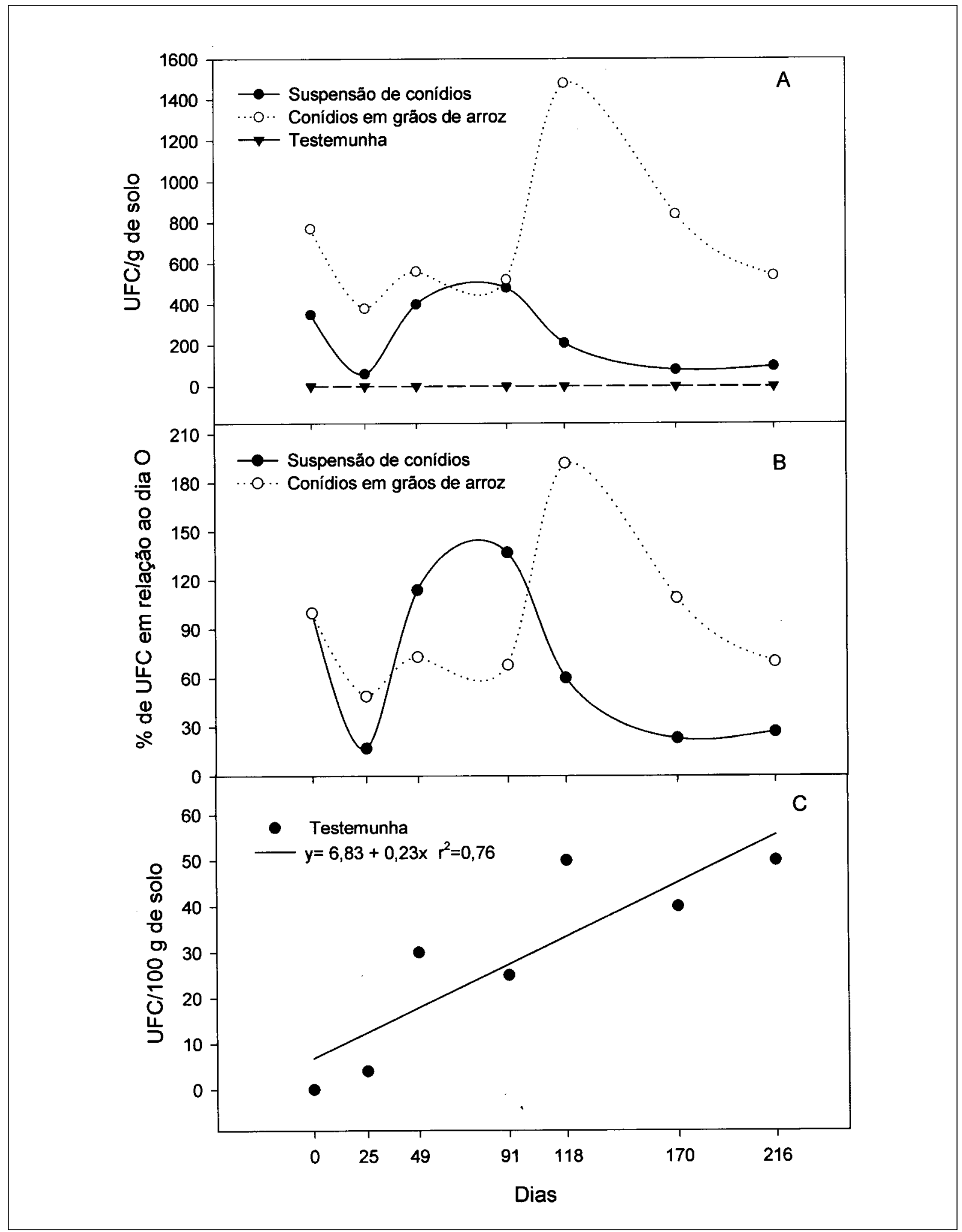

Figura 1 - Número (A) e porcentagem (B) de unidades formadoras de colônias (UFC) de Metarhizium anisopliae (CP 172) no solo, em locais do arrozal irrigado, tratados com a suspensão de conídios e veiculados em grãos de arroz e aumento progressivo de UFC em área testemunha não tratada (C). Rosário do Sul, RS. 1ํ experimento. 1991.

Ciência Rural, v. 34, n. 6, nov-dez, 2004. 
causando morte muito rápida, por toxemia, portanto, impedindo o desenvolvimento do fungo no corpo do inseto. Esta hipótese está baseada no argumento de que, quando fungos entomopatogênicos matam o hospedeiro rapidamente, com freqüência a invasão não é efetiva, talvez devido a uma forte competição com saprófitas e, então, a esporulação é reduzida (HALL \& PAPIEROK 1982); c) resistência natural dos percevejos à infeção fúngica. Baixa infeção de outras espécies de pentatomídeos, como Nezara viridula, (L.), por fungos, também foi observada por MOSCARDI et al. (1985; 1988), sendo posteriormente determinado que alguns compostos químicos presentes na cutícula do inseto reduziram a adesão, germinação e foram fungistáticos a conídios de M. anisopliae (BORGES et al., 1992; SOSA-GÓMEZ et al., 1997).

De modo a explorar o potencial da CP 172 para o controle de $\boldsymbol{T}$. limbativentris, conforme constatado por MARTINS \& LIMA (1994), MARTINS et al. (1997) e também neste trabalho, é necessário empreender estudos sobre processos de infeção do inseto pelo fungo, visando determinar quais fatores podem estar interferindo na sua eficiência, em lavouras comerciais de arroz. Ademais, é necessário identificar outras cepas virulentas ao inseto, avaliando a eficiência de formulações, de doses e de táticas de distribuição, nos arrozais. Neste contexto, recentemente, a cepa Ep TL 01 de $M$. anisopliae destacou-se como a mais eficiente no controle de $\boldsymbol{T}$. limbativentris (PRANDO et al., 2003), tendo já sido estudados, por RAMPELOTTI et al. (2003a,b), sua concentração $\left(\mathrm{CL}_{50}\right)$ e tempo letal $\left(\mathrm{TL}_{50}\right)$.

\section{CONCLUSÕES}

A aplicação de fungos entomopatogênicos sobre indivíduos de $\boldsymbol{T}$. limbativentris, distribuídos de forma agregada, na fase reprodutiva da cultura do arroz irrigado, torna-se factível devido à localização do inseto em locais de alta umidade, sendo possível atingir eficiência de controle (C) satisfatória $(48,2 \% \leq \mathrm{C} \leq 61,8 \%)$, como a obtida por meio da CP 172 de M. anisopliae, tanto na forma suspensão de esporos e em grãos de arroz. Porém, a persistência do fungo, no solo dos arrozais, na entressafra, é maior se aplicado via grãos de arroz cobertos por massa micelar ou conídios.

\section{AGRADECIMENTOS}

Ao Conselho Nacional de Desenvolvimento Científico e Tecnológico (CNPq), pelo apoio concedido ao trabalho.

\section{REFERÊNCIAS BIBLIOGRÁFICAS}

ABBOTT, W.S. A method of computing the effectiveness of an insecticide. Journal of Economic Entomology, v.18, n.2, p.265-267, 1925.

ALVES, S.B. Controle microbiano de insetos. São Paulo : Manole, 1986. 407p.

BOTTON, M. et al. Biologia de Tibraca limbativentris Stal sobre plantas de arroz. Anais da Sociedade Entomológica do Brasil, v.25, n.1, p.21-26, 1996 .

BEILHARZ, V.C. et al. Dodine: a selective agent for certain soil fungi. Transactions of the British Mycological Society, v.79, n.3, p.507-511, 1982.

BORGES, M. et al. Efeito do feromônio de alarme do percevejo verde, Nezara viridula (L.) (Hemiptera: Pentatomidae), sobre o fungo entomopatogênico Metarhizium anisopliae (Metsch.) Sorok. Anais da Sociedade Entomológica do Brasil, v.22, n.3, p.505-512, 1993.

CARBONELL, R.M. et al. Efectividad de Beauveria bassiana (Bals.) Vuill. y Metarhizium anisopliae (Metsch.) Sorok. en el control del Lissorhoptrus brevirostris (Suffr.) (Coleoptera: Curculionidae). Centro Agrícola, v.7, n.1, p.107-121, 1980.

COSTA, E.C.; LINK, D. Avaliação de danos de Tibraca limbativentris Stal., 1860 (Hemiptera: Pentatomidae) em arroz irrigado. Anais da Sociedade Entomológica do Brasil, v.21, n.1, p.187-195, 1992a.

COSTA, E.C.; LINK, D. Dispersão de Tibraca limbativentris Stal, 1860 (Hemiptera: Pentatomidae) em arroz irrigado. Anais da Sociedade Entomológica do Brasil, v.21, n.1, p.197-202, $1992 b$.

FERREIRA, E. et al. Resistência de arroz ao percevejo-do-colmo. Pesquisa Agropecuária Brasileira, v.21, n.5, p.565-569, 1986.

HALL, R.A.; PAPIEROK, B. Fungi as biological control agents of arthropods of agricultural and medical importance. Parasitology, v.84, n.2, p.205-240, 1982.

LINGG, A. J.; DONALDSON, M.D. Biotic and abiotic factors affecting stability of Beauveria bassiana conidia in soil. Journal of Invertebret Pathology, v.38, n.2, p.191-200, 1981.

LINK, D. et al. Alguns locais de hibernação do percevejo da haste do arroz, Tibraca limbativentris na região central do Rio Grande do Sul, Brasil. In REUNIÃO DA CULTURA DO ARROZ IRRIGADO, 22., 1997, Balneário Camboriú. Anais... Itajaí : EPAGRI, 1997. p.322-324

MARTinS, J.F. da S.; LIMA, M.G.A. de. Fungos entomopatogênicos no controle do percevejo-do-colmo do arroz Tibraca limbativentris Stal.: Virulência de isolados de Metarhizium anisopliae (Metsch.) Sorok. e Beauveria bassiana (Bals.) Vuill. Anais da Sociedade Entomológica do Brasil, v.23, n.1, n.39-44, 1994.

MARTINS, J.F. da S. et al. Efeito de Isolados de Metarhizium anisopliae (Metsch.) Sorok. e Beauveria bassiana (Bals.) Vuill. sobre o Percevejo-do-Colmo do Arroz, Tibraca limbativentris Stal. Anais da Sociedade Entomológica do Brasil, v.26, n.2, p.277-283, 1997. 
MARQUES, E.J. et al. Orientações técnicas para produção do fungo entomógeno Metarhizium anisopliae (Metsch.) em laboratórios setoriais. Piracicaba : PLANALSUCAR, 1981. 23p. (Boletim Técnico 2).

MOSCARDI, F. et al. Avaliação de fungos entomógenos sobre percevejos-pragas da soja. In RESULTADOS DE PESQUISA DE SOJA (1984-1985). Londrina, PR, Brasil : Embrapa - Centro Nacional de Pesquisa de Soja, 1985. p.91-98.

MOSCARDI, F. et al. Incidência estacional de fungos entomógenos sobre populações de percevejos-pragas da soja. In RESULTADOS DE PESQUISA DE SOJA (1986-1987). Londrina, PR, Brasil : Embrapa - Centro Nacional de Pesquisa de Soja, 1988. p.90.

PRANDO, H.F. et al. Patogenicidade de isolados de isolados de Beauveria bassiana e Metarhizium anisopliae sobre Tibraca limbativentris (Hemiptera: Pentatomidae). In: CONGRESSO BRASILEIRO DE ARROZ IRRIGADO, 3.; REUNIÃO DA CULTURA DO ARROZ IRRIGADO, 25.; 2003, Balneário Camboriú. Anais... Itajaí : EPAGRI, 2003. p.415-417.

QUINTELA, E.D. Produção de Metarhizium anisopliae (Metsch.) Sor. em quirela de arroz. Anais da Sociedade Entomológica do Brasil, v.23, n.3, p.557-560, 1994.

QUINTELA, E.D. et al. Aplicação de conídios de Beauveria bassiana (Bals.) Vuill. e Metarhiziuma anisopliae (Metsch.) Sor. para controle de larvas de Chalcodermus bimaculatus Boh. (Coleoptera: Curculionidae) no solo. Anais da Sociedade Entomológica do Brasil, v.23, n.3, p.367-377, 1994.
RAMPELOTTI, F.T. et al. Concentração letal de Metarhizium anisopliae isolado Ep TL01, para o controle de Tibraca limbativentris (Hemiptera: Pentatomidae). In: CONGRESSO BRASILEIRO DE ARROZ IRRIGADO, 3.; REUNIÃO DA CULTURA DO ARROZ IRRIGADO, 25.; 2003, Balneário Camboriú. Anais... Itajaí : EPAGRI, 2003a. p.418-419.

RAMPELOTTI, F.T. Determinação do tempo letal do isolado Ep $\mathrm{TL}_{01}$ do fungo Metarhizium anisopliae sobre adultos e ninfas de Tibraca limbativentris. In: CONGRESSO BRASILEIRO DE ARROZ IRRIGADO, 3.; REUNIÃO DA CULTURA DO ARROZ IRRIGADO, 25.; 2003, Balneário Camboriú. Anais... Itajaí : EPAGRI, 2003a. p.421-423.

ROMBACH, M.C. et al. Entomopathogenic fungi in the control of the black bug of rice, Scotinophara coarctata (Hemiptera: Pentatomidae). Journal of Invertebrate Pathology, v.48, n.2, p.174-179, 1986.

SAS INSTITUTE. SAS user's guide: statistics, version 5 edition. Cary, NC : SAS Institute, 1985. 956p.

SOSA-GOMEZ, D.R. et al. Attachment of Metarhizium anisopliae to the southern green stink bug Nezara viridula cuticle and fungistatic effect of cuticular lipids and aldehydes. Journal of Invertebrate Pathology, v.69, n.1, p.31-39, 1997.

TIGANO-MILANI, M.S. et al. Ocorrência natural de Beauveria bassiana (Bals.) Vuill., Metarhizium anisopliae (Metsch.) Sorok. e Paecilomyces sp. em solos de diferentes regiões do Brasil. Anais da Sociedade Entomológica do Brasil, v.22, n.2, p.391-393, 1993. 